\title{
Los orígenes del decreto soviético de legalización del aborto (1920)
}

\author{
[The Origins of the Soviet Decree of Legalization of Abortion (1920)]
}

\author{
Cintia Frencia \\ (Universidad Nacional de Córdoba) \\ cfrencia@gmail.com \\ Daniel Gaido \\ (Conicet-Universidad Nacional de Córdoba) \\ danielgaid@gmail.com
}

\begin{abstract}
Resumen
La Rusia soviética, a iniciativa de las mujeres trabajadoras, fue el primer país en el mundo en legalizar la interrupción voluntaria del embarazo y en permitir su práctica gratuita en hospitales públicos, aun cuando las organizaciones feministas rusas de aquel entonces no incluían dicha demanda en sus programas. El decreto soviético de legalización del aborto coronó toda una serie de medidas legislativas destinadas a instaurar la igualdad legal entre la mujer y el hombre, así como a asegurar la protección legal de las mujeres trabajadoras. En este artículo describimos el proceso que concluyó en la adopción de dicha legislación y analizamos brevemente los resultados de su aplicación en Rusia. La legalización del aborto fue justificada por los representantes del gobierno soviético como una medida requerida por la precaria situación en la que se encontraban las mujeres trabajadoras y campesinas, si bien existió un debate en la Rusia soviética sobre los motivos y la justificación del aborto que intentamos documentar en el presente trabajo. Asimismo, incluimos como apéndices una traducción al español del decreto soviético de legalización del aborto y de las tesis de Nikolai Semashko, el Comisario del Pueblo de Salud Pública, acerca de la posición de la Rusia soviética sobre el tema de la protección maternal e infantil y del aborto.
\end{abstract}

Palabras clave: Revolución bolchevique - Legalización del aborto - Anticoncepción - Planificación del embarazo Liberación de la mujer.

\begin{abstract}
Soviet Russia, at the initiative of working women, was the first country in the world to legalize the voluntary interruption of pregnancy and to allow its free practice in public hospitals, even though the Russian feminist organizations of that time did not include this demand in their programs. The Soviet decree of legalization of abortion crowned a whole series of legislative measures aimed at establishing legal equality between women and men, as well as ensuring the legal protection of working women. In this article we describe the process that concluded in the adoption of such legislation and briefly analyze the results of its application in Russia. The legalization of abortion was justified by the representatives of the Soviet government as a measure required by the precarious situation in which workingclass and peasant women found themselves, although there was a debate in Soviet Russia about the reasons and the justification of abortion that we tried document in the present work. Likewise, we include as appendices a translation into Spanish of the Soviet decree of legalization of abortion and of the theses of Nikolai Semashko, the People's Commissar of Public Health, on the position of Soviet Russia about maternal and child protection and about abortion.
\end{abstract}

Keywords: Bolshevik revolution - Legalization of abortion - Contraception - Pregnancy planning Liberation of women.

Recibido: 04/08/2018

Evaluación: 18/10/2018

Aceptado: 25/10/2018

Anuario de la Escuela de Historia Virtual - Año 9 - N 14 - 2018: pp. 26-52.

ISSN: 1853-7049

http://revistas.unc.edu.ar/index.php/anuariohistoria 


\section{Los orígenes del decreto soviético de legalización del aborto (1920)}

$\mathrm{L}$ a Rusia soviética fue el primer país en el mundo en legalizar la interrupción voluntaria del embarazo: este solo hecho debería atraer la atención hacia la revolución bolchevique de todas las personas interesadas en la liberación de las mujeres y, como parte de la misma, en la legalización del aborto. Sin embargo, a la complejidad del tema -una revolución dirigida por la clase obrera, pero de carácter combinado, democrático-burgués y socialista, en un país con un $84 \%$ de población campesina en 1926 (Lewin, 2005, p. 61)- se agregan las distorsiones prevalecientes en la literatura profesional. Por ejemplo, una especialista en el tema de la revolución rusa y de la mujer afirma que el decreto soviético que legalizó el aborto estuvo "fuertemente influenciado por las nociones patriarcales prevalecientes sobre la maternidad" y que "las discusiones sobre el aborto a principios de la década de 1920, al igual que las que se desarrollaban antes de la Revolución, no se enmarcaban en términos de derechos individuales. El concepto de los derechos reproductivos de la mujer estaba escasamente desarrollado y la noción de los derechos del feto, aún menos" (Goldman, 2011, p. 243).

En realidad, los bolcheviques estaban perfectamente familiarizados con los argumentos feministas, que justamente "se enmarcaban en términos de derechos individuales". ${ }^{1}$ Dado que habían sido miembros de la Internacional Socialista de Mujeres desde su creación en 1907, se diferenciaban tanto programática como ideológicamente del feminismo, como corriente liberal que aspira a hacer extensiva a las mujeres los "derechos del hombre y del ciudadano" de las revoluciones burguesas. Mientras que las feministas apelan a la teoría del derecho natural, en la que se basaban las declaraciones de derechos de las revoluciones burguesas y, según la cual, estos se desprenden de la existencia de una naturaleza humana inmutable y común a todas las personas, las marxistas se basan en la concepción materialista de la historia y por ende ven a la

\footnotetext{
${ }_{1}^{1}$ Antes de la revolución de octubre Rusia conoció cuatro organizaciones feministas: la Sociedad de Ayuda Mutua de las Mujeres Rusas (Русского Женского Взаимно-Благотворительного общества) creada en mayo de 1895 en San Petersburgo y dirigida por Anna Pavlovna Filosofova y Anna Nikitichna Shabanova, la Unión Panrusa para la Igualdad de Derechos de las Mujeres (Всероссийский союз равноправия женщин), о Unión de Mujeres, dirigida por Zinaida Mirovich y Anna Kalmanovich en Moscú, y Liubov Gurevich y Maria Chejova en San Petersburgo, el Partido Progresista de las Mujeres (Женской прогрессивной партии) dirigido por Maria Ivanovna Pokrovskaia, y la Liga Panrusa por la Igualdad de Derechos de las Mujeres (Всероссийская лига равноправия женщин), que el 19 de marzo de 1917 organizó una manifestación de aproximadamente 40.000 mujeres a favor del sufragio femenino (Frencia y Gaido, 2018).
} 
emancipación de la mujer como un producto de la revolución en la situación económica de las mujeres operada por el modo de producción capitalista, que las transformó de esclavas domésticas en esclavas asalariadas $y$, de esa manera, socavó las bases económicas de la antigua familia patriarcal campesina o artesanal. ${ }^{2}$

Históricamente, la humanidad no se desarrolló como una serie de individuos aislados, sino en el marco de comunidades (el clan, la tribu, la aldea, etc.), que fueron disgregándose como producto del desarrollo de la división del trabajo social. Dado que dicho desarrollo no tuvo lugar de una manera consciente, sino como producto de la evolución del intercambio entre productores privados, el resultado de este proceso fue el surgimiento de la individualidad moderna en el marco de una economía mercantil, basada en una producción orientada al intercambio y no al autoconsumo. La producción de mercancías alcanzó su máximo desarrollo con el desarrollo del capitalismo, es decir, de la producción mercantil mediante el trabajo asalariado. Los individuos aislados por la división del trabajo social siguen constituyendo una comunidad de producción, pero no como resultado de una decisión consciente, sino a través de la mediación de los productos de su trabajo, que regulan el proceso de producción independientemente de la voluntad de los productores mismos. La teoría del derecho natural es el reflejo ideológico de este régimen de producción, que no solo oculta el carácter del capitalismo como régimen de explotación del trabajador asalariado, sino también la reificación (cosificación) de las relaciones sociales bajo el mismo.

Los marxistas consideran que todo el sistema de contradicciones de la sociedad capitalista apunta más allá de sí mismo a la restauración de la comunidad humana y a la trascendencia de las divisiones de clase, pero conservando la riqueza de la historia y, por ende, el desarrollo de la individualidad. Pero este desarrollo no es un proceso lineal sino dialéctico, que plantea la necesidad de una reorganización social signada por la toma del poder por los trabajadores y por la instauración de un gobierno obrero, como etapa de transición necesaria entre la sociedad capitalista y la socialista. En este sentido, el planteo de la "autonomía de los cuerpos" ante el Estado zarista o burgués no era idéntico en su contenido al mismo planteo ante un estado obrero, como representación de la voluntad del colectivo de trabajadores. Esta concepción inspiró tanto la legislación bolchevique en torno a la maternidad como el decreto de legalización del aborto, y fue uno de los puntos centrales en el debate sobre los motivos y la justificación del aborto.

\footnotetext{
2 Zetkin, 1907, pp. 3-4. Del análisis de Clara Zetkin, compartido por los bolcheviques, se desprenden toda una serie de conclusiones políticas y organizativas, particularmente la necesidad de una organización propia de las mujeres trabajadoras en el marco de los partidos obreros, que se expresó en las conferencias de mujeres de Partido Socialdemócrata alemán, en la Internacional de Mujeres Socialistas dirigida por Clara Zetkin, en las Comisiones de trabajadoras y en el Departamento para el trabajo entre la Mujer del Partido Bolchevique (Zhetnodel), así como en la Internacional de Mujeres Comunistas, también dirigida por Zetkin. Hemos analizado estas organizaciones, así como sus relaciones con las organizaciones feministas alemanas y rusas, en trabajos anteriores (Frencia y Gaido, 2016; 2018).
} 


\section{Las medidas democráticas adoptadas por los bolcheviques para la liberación de la mujer}

Apenas tomaron el poder, los bolcheviques implementaron una legislación pionera para la liberación de la mujer que incluyó los Decretos sobre el matrimonio civil y el divorcio del 16 y del 18 de diciembre de $1917^{3}$ y el Código de Leyes sobre el estado civil y las relaciones domésticas, el matrimonio, la familia y la tutela, del 22 de octubre de 1918. ${ }^{4}$

El Código de Familia de 1918 abolió el estatus legal inferior de las mujeres y estipuló la igualdad de la mujer y del hombre ante la ley. Dicho Código proclamó que solo el consentimiento mutuo de un hombre y una mujer podía ser la base del matrimonio, y que solo el matrimonio civil era legal. La autoridad sobre el registro de matrimonio fue transferida de las autoridades religiosas al estado soviético. El Código de familia también eliminó las distinciones legales entre hijos legítimos e ilegítimos para que todos los niños fueran iguales ante la ley, legalizó el divorcio a petición de cualquiera de los cónyuges sin necesidad de fundamentar sus motivos, y estipuló la obligatoriedad de una pensión alimenticia por un período ilimitado en casos de necesidad, tanto para la mujer como para el hombre.

A esta legislación debe agregarse la protección legal de la mujer trabajadora, incluyendo el Decreto sobre la jornada laboral de ocho horas del 29 de octubre de 1917 (que prohibió el trabajo nocturno de la mujer, así como las horas extras), ${ }^{5}$ y el Código de Trabajo de diciembre de 1918, el cual estipulaba que las trabajadoras tenían derecho a una licencia por maternidad de 112 días, 8 semanas antes y 8 semanas después del parto, percibiendo íntegramente su salario, y que a toda trabajadora madre de un hijo lactante se le debía otorgar cada tres horas un descanso de media hora para amamantar a su hijo. ${ }^{6}$

\footnotetext{
3 Декрет ВЦИК и СНК о расторжении брака. 16 декабря 1917 г. [Decreto del Comité Ejecutivo Central de toda Rusia y del Consejo de Comisarios del Pueblo sobre el divorcio (16 de diciembre de 1917)]. URL: http://www.hist.msu.ru/ER/Etext/DEKRET/17-12-16.htm.

Декрет о гражданском браке, о детях и о ведении книг актов состояния. 18 декабря 1917 года. [Decreto soviético sobre el matrimonio civil, los niños y el registro civil (18 de diciembre de 1917)]. URL: http://istmat.info/node/28231.

4 Всероссийский центральный исполнительный комитет (ВЦИК): Кодекс законов об актах гражданского состояния, Брачном, Семейном и Опекунском праве. (22 октября 1918 года.) [Сomité Ejecutivo Central Panruso (VTsIK): Código de leyes sobre actos de estado civil, matrimonio, familia y derecho custodio. (22 de octubre de 1918)]. URL: http://istmat.info/node/31624.

El Código de Familia de 1918 fue traducido al inglés como The Marriage Laws of Soviet Russia: Complete Text of First Code of Laws of the Russian Socialist Federal Soviet Republic dealing with Civil Status and Domestic Relations, Marriage, the Family and Guardianship. New York: Russian Soviet Government Bureau, 1921. URL: https://archive.org/details/marriagelawsofso00sovi.

5 Декрет Совета Народных Комиссаров: О восьмичасовом рабочем дне) [29 октября 1917 г.] [Decreto del Consejo de Comisarios del Pueblo: Sobre la jornada laboral de ocho horas (29 de octubre de 1917)]. URL: http://constitution.garant.ru/history/act1600-1918/5306/.

${ }^{6}$ Кодекс законов о труде 1918 года. URL: http://www.hist.msu.ru/Labour/Law/kodex_18.htm.
} 
En 1923, la República Soviética Rusa incluso adoptó un estatuto pionero contra el acoso sexual de mujeres; cuando en 1926 se publicó un Código Penal revisado de la RSFSR, que reemplazó al Código Penal ruso de 1922, la enmienda de 1923 al artículo 169, que prohibía el acoso sexual a las mujeres, se transformó en el artículo 154. La edición de 1926 del Código Penal ruso declaraba lo siguiente en su artículo 154: "La compulsión de una mujer a entablar relaciones sexuales o a satisfacer el deseo sexual en otra forma por parte de una persona de la cual la mujer era material o profesionalmente dependiente, [será penalizada con] encarcelamiento hasta cinco años" ${ }^{7}$

En el marco de estas medidas democráticas para la liberación de las mujeres adoptadas por el gobierno bolchevique debe ser visto el Decreto sobre la legalización del aborto del 10 de noviembre de 1920.

\section{La iniciativa de las trabajadoras en la adopción del decreto soviético sobre el aborto}

Aunque el estatuto que despenalizó la realización del aborto con fines no médicos no fue adoptado inmediatamente después de la toma del poder por los bolcheviques, de hecho, ninguna mujer o médico fue procesado por realizar un aborto después de octubre de 1917 -de la misma manera que ningún homosexual fue procesado, aunque la homosexualidad no fue despenalizada formalmente hasta la adopción del primer Código Penal de la Rusia soviética el 1 de junio de 1922 (Healey, 2018).

El hecho de que la Rusia soviética haya sido el primer país en el mundo en legalizar la interrupción voluntaria del embarazo no fue casual: Lenin y los bolcheviques venían defendiendo el derecho al aborto ya antes de la revolución de octubre. En mayo de 1913, por ejemplo, Lenin escribió: “Exigir la abolición absoluta de todas las leyes contra el aborto o contra la difusión de literatura médica sobre medidas anticonceptivas. Semejantes leyes no muestran sino la hipocresía de las clases dominantes... Libertad para la propaganda médica y la protección de los derechos democráticos elementales de los ciudadanos, hombres y mujeres" (Lenin, 1913, p. 480).

No solamente los bolcheviques discutieron el tema del aborto en la Rusia zarista, por supuesto, aunque el tema no estaba en la agenda de las organizaciones feministas. La sección rusa de la Unión Internacional de Criminólogos, reunida en 1914, recomendó que el aborto fuera eliminado de la lista de delitos penales. La sociedad médica Pirogov

Versión inglesa: The Labor Laws of Soviet Russia. With a supplement on The Protection of Labor in Soviet Russia, by S. Kaplun, of the Commissariat of Labor. $4^{\text {th }}$ ed. New York: Russian Soviet Government Bureau, 1921, pp. 15, 27, 56. URL: https://archive.org/details/LaborLawsOfSovietRussia.

7 “154. Понуждение женщины к вступлению в половую связь или к удовлетворению половой страсти в иной форме лицом, в отношении коего женщина являлась материально или по службе зависимой, - лишение свободы на срок до пяти лет." Уголовный Кодекс РСФСР редакции 1926 [El Código Penal de la República Socialista Federativa Soviética de Rusia de 1926, artículo 154]. URL: https://coollib.com/b/124310/read. 
había llamado la atención sobre el problema una década antes. En su noveno Congreso, celebrado en 1904, se creó una comisión especial para examinar la cuestión del aborto desde el punto de vista médico y social. En su $12^{\circ}$ Congreso, celebrado en 1913, el tema del aborto fue uno de los puntos principales en la agenda. Después de un largo debate, los delegados aceptaron una propuesta formulada por la Sociedad Médica de Omsk según la cual el aborto ya no debía considerarse un delito penal para las mujeres y los médicos que practicaban abortos solo podían ser demandados si realizaban la operación por razones mercenarias (Waters, 1985, pp. 251-251). ${ }^{8}$ Pero sin la toma del poder por los bolcheviques y las iniciativas que la revolución de octubre despertaron en las mujeres trabajadoras estos debates seguramente no habrían tenido efecto alguno en la esfera legislativa, como sucedió en el resto de los países hasta los años '70.

Según el testimonio de Alexandra Kollontai, la Comisaria del Pueblo para la Asistencia Pública, la legislación sobre el aborto fue adoptada por el gobierno bolchevique a iniciativa de las obreras. En 1921, Kollontai describió de la siguiente manera el proceso que condujo al Partido Bolchevique primero a crear las Comisiones de trabajadoras y el Departamento para el trabajo entre la Mujer (Zhetnodel), y finalmente a adoptar el decreto legalizando el aborto y estableciendo su práctica gratuita en los hospitales:

"Por iniciativa del grupo de mujeres comunistas en Moscú y con el pleno apoyo del Comité Central del Partido Comunista fue organizado en noviembre de 1918 en Moscú, el Primer Congreso panruso de obreras y campesinas [I Всероссийский съезд работниц и крестьянок]. Asistieron más de un millar de delegadas elegidas en asambleas de obreras y campesinas. Esta conferencia no solo tuvo una importancia crítica como propaganda, sino que sentó las bases de la organización en el Partido Comunista de un aparato especial en el Comité Central para la dirección del trabajo entre las mujeres en toda Rusia [Zhenotdel]. La formación de un aparato especial dentro del partido, con miras a la participación de las masas femeninas en la construcción de la República del trabajo y en la lucha por el comunismo fue así oficialmente reconocida por el partido.

En un primer momento, fueron las Comisiones para la agitación y la propaganda entre las trabajadoras [Комиссии по агитации и пропаганде среди работниц], organizadas en torno a los comités del partido, las que llevaron a cabo este trabajo. El lema de estas comisiones es: agitación, no solo de palabra, sino por la acción, lo que significaba la formación de comunistas conscientes y activas mediante la participación de las campesinas y de las trabajadoras en el trabajo vivo y activo de los soviets. Con este fin, las Comisiones de trabajadoras [Комиссии работниц] crearon un dispositivo especial que conecta el partido con las amplias masas atrasadas de las trabajadoras, a saber, la asamblea de delegadas. Cada fábrica, cada taller con cincuenta trabajadoras elige su representante para la asamblea de delegadas de las trabajadoras. Las delegadas son elegidas por tres meses. Están obligadas a asistir a

\footnotetext{
8 Para los debates prerrevolucionarios en Rusia sobre la legalización del aborto, ver: Engelstein, 1991.
} 
las reuniones semanales, donde se ponen al corriente de los acontecimientos políticos actuales, trabajan en diferentes áreas de la construcción del Estado soviético, en particular las relativas a la educación social, la alimentación social, la protección de la maternidad y otras áreas de la tarea soviética que contribuyen directamente a la emancipación económica de las trabajadoras. [...]

A medida que el trabajo del partido entre las mujeres aumentaba, surgió la necesidad de ordenar el trabajo, de profundizarlo y armonizarlo. En el otoño de 1919, el partido reorganizó sus comisiones de trabajadoras en el Departamento para el trabajo entre la Mujer (Zhetnodel) [Отдел по Работе Среди Женщин (Женотдел)]. Este Departamento está representado hoy en día en cada comité del partido, empezando por el Comité Central y terminando en los comités de pueblo, de barrio y de distrito.

Los Departamentos de trabajadoras [Отделы работниц] no solo involucran a las obreras y campesinas en el partido y en los órganos de la construcción soviética, formando así comunistas activas, sino que toman la iniciativa en la construcción del sistema soviético, planteando ante el partido y ante los órganos soviéticos los problemas relativos a la cuestión de la emancipación total y práctica de la mujer. De este modo, por iniciativa de los Departamentos de trabajadoras se adoptó la ley sobre la legalización del aborto..." (Kollontai 1921d, pp. 8-10, énfasis nuestro).

Cuando la guerra civil y la guerra ruso-polaca que le siguió inmediatamente comenzaron a llegar a su fin, las secciones femeninas del Partido Bolchevique desviaron su atención de las tareas nacionales (como el apoyo al Ejército Rojo) hacia la resolución de problemas "femeninos", especialmente la protección del trabajo femenino bajo las condiciones de reclutamiento laboral, introducido a nivel nacional en enero de 1920 en el marco del comunismo de guerra, y las cuestiones relativas al aborto, la maternidad y la prostitución (Wood, 1997, p. 48).

\section{Los debates que precedieron a la adopción del decreto soviético sobre el aborto}

En noviembre de 1919, el experto forense Dr. la. Leibovich redactó una serie de tesis recomendando la legalización del aborto. En febrero de 1920, la División Médica del Comisariado del Pueblo para la Salud Pública distribuyó las tesis de Leibovich a todos los departamentos de salud con instrucciones de solicitar las opiniones de los trabajadores de la salud, de la justicia, los trabajadores sociales y las representantes del Departamento para el trabajo entre la Mujer del Partido Comunista. El escrutinio reveló que la comunidad médica soviética estaba mayoritariamente opuesta a la introducción de la nueva política (Gross Solomon, 1992a, p. 75).

En los meses de abril a julio de 1920, el Departamento para el trabajo entre la Mujer del Partido Comunista organizó tres reuniones con representantes del Comisariado del Pueblo de Salud Pública y su División para la Protección de la Maternidad y la Infancia para discutir la cuestión del aborto. Las reuniones se llevaron a cabo el 14 de abril, el 2 de junio y el 3 de julio de 1920. Muchas figuras destacadas del Zhenotdel tomaron parte 
en la discusión. Participaron activamente en las mismas el Comisario del Pueblo de Salud Pública Nikolai Semashko, la directora de la Sección de Protección de la Maternidad Vera Lebedeva, y dirigentes bolcheviques destacadas como Inessa Armand, Alexandra Kollontai, Nadezhda Krupskaia, Olga Kameneva y Vera Golubeva.

Durante dichas reuniones, Semashko y Lebedeva presentaron una serie de tesis para la discusión. ${ }^{9}$ Comenzaron mencionando la peligrosidad del aborto clandestino para la salud de la mujer y en consecuencia la necesidad de legalizarlo. El punto principal de cualquier legislación, argumentaron, no debía ser la protección de la mujer individual y su derecho a terminar un embarazo, sino la protección del colectivo y la salud de la madre por el bien de las generaciones futuras. El colectivo y la "conveniencia estatal" (государственная целесообразность), en otras palabras, debían tener prioridad sobre los "derechos individuales" (права личности) (Wood, 1997, p. 107, p. 252, nota 43).

Los participantes en las reuniones señalaron que criminalizar el aborto conllevaba graves peligros para la salud de la mujer, ya que conducía a su práctica clandestina. Si el aborto seguía siendo ilegal, las mujeres continuarían buscando ayuda de las parteras de pueblo (повитухи) у de las curanderas (знахарки). Las autoridades médicas soviéticas insistieron en la necesidad de que tales cuestiones estuvieran en manos de profesionales y en que los abortos se practicaran en las instituciones médicas estatales. Al mismo tiempo, tanto Semashko como Lebedeva creían que las guarderías e instituciones de maternidad estatales podían servir como factores disuasivos en aquellos casos en los que las mujeres se practicaban un aborto debido a la compulsión de factores materiales externos.

No todos los presentes en las reuniones estuvieron de acuerdo en que el aborto debía ser legalizado. Cherliunchakevich, un representante del Comisariado de Justicia, argumentó que el aborto debía seguir siendo un acto criminal que solo sería permitido por una comisión especial, ya que el orden soviético no debía apoyar nada que pudiera conducir a "la destrucción del embarazo". Preobrazhensky apoyó dicha noción, llamando a crear "tribunales sociales" especiales para decidir en qué casos debía practicarse el aborto.

Quienes se opusieron a dichas comisiones afirmaron que las mujeres preferirían practicarse abortos clandestinos, incluso a riesgo de morir, antes de contar aspectos íntimos de sus vidas a un consejo médico. Además, la maternidad debía ser vista como un derecho y no como un deber de la mujer libre y, por lo tanto, no debía ser regulada de esta manera. Inessa Armand incluso propuso un nuevo eslogan: "Bajo el orden

\footnotetext{
9 Las tesis de Semashko para el Zhenotdel aparecen reproducidas en el Apéndice II, porque fueron presentadas como preludio al Decreto soviético de legalización del aborto en la edición alemana del mismo publicada en la revista editada por Clara Zetkin, Die kommunistische Fraueninternationale.
} 
comunista, es impensable que el nacimiento de un niño sea una forma de reclutamiento laboral" (Wood, 1997, pp. 107-108).

En el verano de 1920, tanto Krupskaya como Semashko instaron a la descriminalización del aborto en las páginas de la revista Kommunistka. En junio de 1920, en un artículo titulado "La guerra y el parto", Krupskaya afirmó que la mujer que está embarazada ya siente los preparativos en su organismo para el parto y la lactancia. "Subjetivamente", comentó Krupskaya, "la madre siente la interrupción de ese proceso como un crimen contra sí misma y contra el niño". Pero Krupskaya declaró explícitamente su opinión de que no era un crimen destruir al feto, ya que todavía formaba parte del organismo de la madre y aún no era un ser vivo (Крупской, 1920).

Dos meses después, Semashko lamentó la falta de discusión sobre este tema en las asambleas de mujeres. El Comisario del Pueblo de Salud Pública instó a la creación de hogares especiales para las madres jóvenes, donde pudieran descansar durante cuatro meses antes del parto y un mes después, como medio para evitar los abortos, particularmente entre las mujeres que aún no habían tenido hijos. Si una mujer se avergonzaba de ingresar en una institución de ese tipo en su propio distrito, las secciones de mujeres del Partido Comunista podían enviarla a una en otro distrito. Aunque Semashko creía que legalizar el aborto era el paso correcto, hizo referencias a cartas que había recibido de médicos que no deseaban realizar abortos debido a objeciones de conciencia y de una mujer que escribió sobre los conflictos entre la maternidad y la afiliación partidaria. Al mismo tiempo que abogaba por la legalización del aborto, Semashko insistió en la "obligación moral" de las mujeres de tener hijos, de criar a la próxima generación. Repitió sus tesis de la reunión de Zhenotdel, incluyendo el rechazo a la prioridad de los "derechos individuales" de las mujeres en la cuestión de la maternidad y del aborto. ${ }^{10}$

Según Kollontai, por su parte, las secciones de mujeres del Partido tenían que fijarse como objetivo la emancipación real y completa de las mujeres, al mismo tiempo que defendían por sus intereses inmediatos. En noviembre de 1920, Kollontai explicó los problemas que tenía en mente como aquellos que "surgen de las especificidades del sexo femenino (por ejemplo, la maternidad, la protección del trabajo femenino, la legislación sobre la cuestión del aborto)" y los que "están conectados con la posición particularmente desfavorable de las mujeres, su propia esclavización o desigualdad, y los vestigios del pasado burgués -por ejemplo, la cuestión de la prostitución". ${ }^{11}$ En discusiones que tuvieron lugar en la sección de mujeres del Partido Comunista en 1920, varios de los

\footnotetext{
${ }^{10}$ Semashko, H. (1920). Еще о больном вопросе, Коммунистка 3 анд 4, Ауг.-Септ, пп. 19-21 [N. Semashko (1920). Más sobre la cuestión de la enfermedad, Kommunistka, 3 y 4, agosto-septiembre, pp. 19-21], citado en: Wood, 1997, p. 108 y nota 49, p. 252.

${ }^{11}$ A. Kollontai (1920). Задачи отдела по работе среди женшчин: Las tareas del departamento de trabajo entre mujeres, Kommunistka, 6, noviembre, pp. 2-3, citado en: Wood, 1997, p. 102, p. 250, nota 14.
} 
presentes (especialmente Inessa Armand) abogaron por la preparación de folletos especiales sobre medidas anticonceptivas como alternativa al aborto. Krupskaya argumentó públicamente que la anticoncepción era más segura que el aborto (Крупской, 1920).

Al mismo tiempo, el gobierno bolchevique enfatizó la necesidad de crear instituciones para madres e infantes como un incentivo positivo para desalentar a las mujeres a practicarse un aborto. De hecho, las autoridades hicieron todo lo posible para colocar la legalización del aborto dentro del contexto de políticas diseñadas para proteger a las mujeres como madres. Promulgaron una amplia gama de decretos e iniciaron campañas "en defensa de la maternidad y de la infancia". En marzo y abril de 1920 las secciones de maternidad y niños fueron formalmente transferidas del Comisariado de Trabajo y Bienestar Social al Comisariado de Salud Pública bajo Semashko. El 1 de julio de 1920, un nuevo decreto que protegía a las mujeres embarazadas no solo reafirmó el derecho a la licencia de maternidad por ocho semanas para las trabajadoras que realizaran trabajos físicos (y de seis semanas para aquellas que realizaran trabajos intelectuales), sino que también las liberó de todas las formas de reclutamiento laboral durante ese tiempo, con restricciones significativas en el servicio requerido en los meses anteriores a ese periodo.

En septiembre de 1920, las secciones de mujeres del Partido Comunista publicaron un nuevo decreto en Pravda sobre la protección de las mujeres embarazadas, el cual insistía en la protección de las generaciones futuras de trabajadores y en la necesidad de reducir las altas tasas de mortalidad infantil en Rusia. Para lograr esto, los órganos políticos locales debían aplicar los controles más estrictos a fin de garantizar que las mujeres embarazadas fueran liberadas del trabajo remunerado y de la conscripción laboral en el momento apropiado, que fueran transferidas de trabajos pesados a puestos más ligeros, que les fueran asignados solo turnos diurnos y que se les otorgaran toda una serie de beneficios, como prioridad en las colas para la comida, boletos de tren y lugares en los tranvías. Un decreto del 7 de octubre de 1920 inició "La semana del niño", que fue celebrada del 12 al 18 de noviembre. Otro decreto del 11 de noviembre de 1920 estipuló medidas para proteger el trabajo y la salud de las madres lactantes (Wood, 1997, pp. 110111). Este fue el preludio a la adopción del decreto soviético de legalización del aborto.

\section{"Sobre la protección de la salud de las mujeres" (18 de noviembre de 1920)}

La firma del edicto legalizando el aborto se produjo rápidamente. En la primavera de 1920, comenzaron a circular rumores sobre un decreto que legalizaría el aborto. El tema fue discutido el 3 de noviembre de 1920 en una reunión de la Sociedad de Obstetras y Ginecólogos de Moscú a la que asistió, entre otros, el Comisario del Pueblo de Salud Pública, N.A. Semashko. Esta reunión debía continuar el día 17 de dicho mes, pero se 
pospuso hasta el día 25. En el ínterin, el decreto fue firmado (Gross Solomon, 1992b, p. 476, note 5).

El decreto de legalización del aborto, publicado en el periódico Noticias del Comité Ejecutivo Central de los Soviets el 18 de noviembre de 1920, contenía la mayoría de las disposiciones que Semashko y otros habían defendido, incluyendo el énfasis en la descriminalización del aborto como un mal menor comparado con los abortos clandestinos ilegales. El decreto oficial fue firmado por Semashko y Kurski, el Comisario del Pueblo de Justicia, con la intención de "proteger la salud de las mujeres". Con este decreto, la Rusia soviética se convirtió en el primer país del mundo en el que cualquier mujer podía solicitar una interrupción voluntaria del embarazo. Los profesionales médicos creían que los abortos ilegales a menudo dañaban la salud de las mujeres porque muchos procedimientos ilegales eran autoinducidos o realizados por practicantes no especializadas (бабки: “abuelas") y, en ese entonces, no existían antibióticos para prevenir las infecciones cuando las operaciones se realizaban en condiciones no sanitarias.

El decreto se refiere al aborto como un "mal" (3/0) y a la necesidad de combatir ese mal a través de la propaganda masiva contra el aborto. Por lo tanto, aunque el decreto se comprometía a "permitir que este tipo de operaciones se practique libremente y sin ningún cargo en los hospitales soviéticos", también expresaba la intención del gobierno soviético de luchar contra este fenómeno mediante la planificación del embarazo. Además, insistía en que los abortos solo podían realizarse en hospitales soviéticos por médicos calificados; nadie más, incluidas las parteras, podía realizarlos. El decreto enfatizaba la posición de debilidad de las mujeres, su condición de "víctimas de charlatanes mercenarios y a menudo ignorantes", y de las infecciones, incluso muertes, que sufrían como resultado de abortos llevados a cabo en forma clandestina. La responsabilidad general de supervisar el funcionamiento de la ley de aborto recayó en el Comisariado del Pueblo de Salud Pública y en su División para la Protección de la Maternidad y la Infancia. ${ }^{12}$

El decreto de 1920 no fue promulgado en nombre de los derechos de las mujeres sobre sus propios cuerpos. Unos pocos meses después de su promulgación, el Comisario del Pueblo de Salud, Semashko, declaró que solo los anarquistas pequeñoburgueses podían desear tal cosa. ${ }^{13}$ Como veremos, aunque esta era la posición oficial de los representantes del gobierno soviético, dentro de la Rusia soviética hubo un debate en torno a las causas y la justificación de la legalización del aborto. Pero el Departamento para el Trabajo entre la Mujer del Partido Comunista no consideró incoherente apoyar el decreto de

\footnotetext{
${ }_{12}$ Para una traducción del decreto soviético legalizando el aborto, ver el Apéndice I al presente trabajo.

${ }^{13}$ N.A. Semashko (1920). Больной вопрос ["Una cuestión dolorosa"], Izvestiia VTSiK, 151, 11 de julio, p. 3; N.A. Semashko (1920). Еще о больном вопросе ["Mas sobre la cuestión dolorosa"], Kommunistka, 3-4, pp. 19-21, citado en: Gross Solomon, 1992a, p. 75, nota 8.
} 
legalización del aborto de 1920 y, al mismo tiempo, agitar por la preservación de la maternidad, ya que la verdadera elección no era entre el aborto y el mantenimiento de altas tasas de natalidad, sino entre abortos legales (seguros) y abortos clandestinos. ${ }^{14}$

\section{La aplicación del decreto de legalización del aborto}

La aplicación del decreto tropezó con enormes dificultades, empezando por el hecho de que en miles de pueblos y municipios no había ningún hospital, y mucho menos uno con un médico capacitado para realizar abortos. Una vez legalizado el aborto, a pesar de las mejores intenciones de los funcionarios de salud, muchas áreas recurrieron a comisiones médicas especiales para determinar en qué casos se practicaría el aborto, debido a la grave escasez de camas en los hospitales. El aborto se practicaba en el $99,6 \%$ de los casos dentro de los primeros tres meses del embarazo, habitualmente sin anestesia y sin interrupción, en el transcurso de una sesión (Ruben-Wolf, 1929, p. 6).

El 9 de enero de 1924, en el contexto del brutal "plan de ajuste" conocido como la Nueva Política Económica o NEP (impuesto al gobierno bolchevique por el colapso económico del comunismo de guerra y por las rebeliones campesinas contra las requisas de grano, tales como la dirigida por Antonov en la provincia de Tambov, así como por la revuelta de los marineros de Kronstadt de marzo de 1921), el derecho a practicarse gratuitamente un aborto fue restringido a quienes tenían seguro médico en sus lugares de trabajo o a través de sus maridos. Incluso en estos casos, se dio prioridad a ciertas categorías: (1) mujeres solteras desempleadas que recibían ayuda a través de las bolsas de trabajo; (2) trabajadoras solteras que ya tenían un hijo; (3) mujeres trabajadoras con varios hijos (es decir, al menos tres); y (4) esposas de trabajadores con varios hijos. Otra circular de esta época agregó categorías adicionales de mujeres a las que se les permitía abortar en forma gratuita en los hospitales estatales: mujeres cuyo embarazo fue resultado de violación, fuerza o engaño, o de su posición indefensa, de su estado inconsciente o de debilidad mental; menores solteras; mujeres cuyo embarazo ocurrió como resultado de la manipulación de su dependencia material; mujeres solteras y desempleadas, especialmente aquellas en circunstancias materiales difíciles; familias que vivían de un salario con tres o más hijos para las cuales cualquier aumento adicional en el tamaño de la familia causaría considerable daño material, especialmente cuando había niños menores de edad; familias donde ambos cónyuges habían experimentado un desempleo prolongado; por razones médicas (tuberculosis, pelvis estrecha, enfermedad renal, etc.) o por motivos de eugenesia (epilepsia, enfermedad mental, sordera hereditaria, etc.). En noviembre de 1924 se establecieron comisiones regionales

${ }^{14}$ Gross Solomon, 1992a, p. 61. El censo de 1926 mostró que las mujeres soviéticas daban a luz a un promedio de 5,37 niños (Nakachi, 2016, p. 309). 
de aborto que otorgaban permisos para tener acceso a la interrupción voluntaria gratuita del embarazo y supervisaban que se estuviera respetando la lista de prioridades establecida.

A pesar de todos los obstáculos materiales, el aborto fue gradualmente sacado de la clandestinidad y practicado gratuitamente en los hospitales públicos. En 1923, alrededor del 57\% de los abortos aún se realizaban fuera de los hospitales. En el transcurso de la década de 1920, esta cifra comenzó a descender al 43\% en 1924, al 15.5\% en 1925, al 12\% en 1926 y al 10\% en 1932 (Conius, 1933, p. 37). Fuentes de archivo corroboran estos datos e indican que, mientras que en 1923 el 42\% de los abortos fueron practicados fuera de los hospitales, la cifra descendió al 37\% en 1924, al 30\% en 1925, al 25\% en 1926 y al 24\% en $1927 .{ }^{15}$

Al mismo tiempo, con la recuperación económica que siguió a la aplicación de la NEP, el gobierno soviético comenzó a enfatizar cada vez más la planificación del embarazo. El control de la natalidad fue legalizado en la Unión Soviética en 1923. Desde el otoño de 1924 en adelante, la rama de Leningrado de la División para la Protección de la Maternidad y la Infancia permitió que las comisiones de aborto tomaran la iniciativa y sugirieran la anticoncepción como una alternativa al aborto, y la Comisión Científica Central para el Estudio de los Anticonceptivos se estableció en 1925 bajo la égida de la División de Protección de la Salud y la Infancia del Comisariado de Salud Pública (Gross Solomon, 1992a, p. 61, 78, nota 67, p. 66).

\section{El debate sobre los motivos y la justificación del aborto}

En un ciclo de conferencias dictado en la primavera de 1921 ante mujeres pertenecientes a las secciones femeninas del Partido Comunista, originalmente publicadas con el título La posición de la mujer en la evolución de la economía, Kollontai se refirió a "la postura del gobierno soviético frente al aborto", y afirmó que "en la república de trabajadores existe una ley del 18 de noviembre de 1920 que legaliza la interrupción del embarazo" porque "la mojigatería y la hipocresía son ajenas a la política proletaria". Kollontai creía que existía un "instinto maternal natural de la mujer" y que la maternidad era "un deber social". No obstante, pensaba que el aborto era producto "de la posición insegura de las mujeres", y que "mientras no se hayan asegurado condiciones de vida adecuadas para las mujeres, los abortos seguirán practicándose". La prueba estaba en que el aborto se practicaba "en todos los países, y no hay leyes ni medidas punitivas que hayan logrado erradicarlo". Por lo tanto, la verdadera opción no era entre la práctica o no del aborto, sino entre el aborto clandestino y el aborto practicado "en condiciones médicas adecuadas", que era "menos dañino y peligroso" para la salud de la mujer. El gobierno

${ }^{15}$ Wood, 1997, p. 253, nota 53. Para una descripción detallada de la aplicación del derecho al aborto entre 1920 y 1936, ver: Goldman, 2011, pp. 241-274. 
bolchevique entendía que el aborto solo desaparecería cuando Rusia dispusiera de una red de instituciones que protegieran la maternidad y socializaran el cuidado y la educación de los niños, lo cual permitiría "compatibilizar la maternidad con el trabajo para el colectivo y así eliminar la necesidad del aborto". Hasta que no se dieran esas condiciones, "el poder soviético permitió que el aborto se realizara abiertamente y en condiciones clínicas adecuadas". Kollontai concluía afirmando que la emancipación de las mujeres solo podía completarse cuando se produjera "una transformación fundamental de la vida cotidiana; la cual cambiará solo con un cambio profundo de toda la producción y con el establecimiento de una economía comunista". ${ }^{16}$

En el mismo sentido, en un artículo titulado "Las dos revoluciones de noviembre y las mujeres" (en referencia a la revolución de octubre/noviembre de 1917 en Rusia y de noviembre de 1918 en Alemania), publicado en la revista Die Kommunistische Fraueninternationale (La Internacional de Mujeres Comunistas) en noviembre de 1921, su editora, Clara Zetkin, dijo lo siguiente sobre el decreto soviético de legalización del aborto:

"Es indiscutible que todo lo que proporciona la Rusia soviética para la protección y atención de la madre y del niño son solo comienzos, en comparación con las necesidades sociales. Estos comienzos son complicados y obstaculizados por las necesidades de la economía destrozada, por la traicionera lucha de los enemigos en el país y más allá de sus fronteras. Sin embargo, estos comienzos son enormes; expresan una voluntad creativa fuerte e indomable, llena de promesas para el futuro de la madre y del niño. En el áspero presente, el gobierno soviético toma en cuenta el hecho de que el Estado de los trabajadores y de los campesinos lamentablemente aún no puede garantizar a todas las madres y a sus hijos la protección y el cuidado adecuados. Es por eso que ha liberado a la mujer de la espantosa compulsión de ser madre, cuando está segura de que al fruto de su cuerpo solo le espera la miseria más amarga, de que faltan todas las condiciones para su desarrollo y para una infancia y una juventud felices y saludables. En la Rusia soviética, el aborto está legalizado, pero solo si lo practica un médico en un hospital público. La mujer que es operada allí es liberada de su deber de trabajar por tres semanas, durante las cuales recibe su salario completo. El aborto artificial se castiga severamente si es practicado fuera del hospital por un médico, cirujano o partera. Cualquier mujer que desee interrumpir su embarazo a través de la intervención del médico debe ser debidamente informada sobre las posibles consecuencias de la operación, así como sobre todas las medidas de protección y de cuidado adoptadas por el Estado en favor de la madre y del niño. Una amplia propaganda está destinada a informar a las mujeres en edad fértil en la ciudad y en el campo sobre estos temas, al mismo tiempo que les llama la atención sobre la gran importancia social de la maternidad y de tener una amplia descendencia. La legalización del aborto artificial como medida de emergencia no

${ }^{16}$ Kollontai, 1922. URL: http://books.e-heritage.ru/book/10077007. Las ediciones en castellano suelen llevar el título La mujer y el desarrollo social. 
debe abrir la puerta a la inclinación irreflexiva, frívola y egoísta a escapar de las cargas y obligaciones del embarazo y de la maternidad" (Zetkin, 1921).

Pero es importante señalar que no existía unanimidad sobre este punto, y que los motivos y la justificación del aborto fueron objeto de debate dentro de la Unión Soviética.

En 1922, por ejemplo, el médico ruso A. Rivkin publicó un folleto de 23 páginas titulado Una mirada moderna sobre el aborto involuntario, en el que argumentó que "solo por el hecho de que la mujer es capaz de dar a luz, el Estado no puede exigir que la mujer dé a luz, no la puede convertir en una máquina de hacer bebés". El control del medio ambiente era, en su opinión, incompleto sin los medios para regular la fertilidad. “¿Debe la humanidad (en este caso, la mujer) que es señora de la naturaleza, que está acostumbrada a someter a la naturaleza, comportarse en este particular como víctima de la naturaleza, condenada a aceptar las consecuencias de por vida de un incidente pasajero infeliz? Seguramente no". En opinión del Dr. Rivkin, el ejercicio del control era una prerrogativa de la mujer, y sus derechos invalidaban a los del Estado en este asunto. La portada de su folleto llevaba el encabezamiento "Durante el período de la vida intrauterina, el derecho sobre el feto pertenece solo a la madre", y en su texto continuaba discutiendo y fundamentando esta afirmación: "El colectivo de mujeres, los sindicatos de mujeres trabajadoras, los zhenotdely y otras organizaciones de mujeres, después de haber extraído de este material todo lo que encuentren útil para ellas mismas, y de que hayan rechazado lo que tal vez los hombres han malinterpretado, emitirán su juicio final, un juicio que responda plenamente a los intereses de las mujeres, y debemos aceptar este juicio como vinculante y definitivo".${ }^{17}$ Fue a través de un prisma similar que feministas extranjeras, tales como Helene Stöcker, vieron la legalización del aborto en la Rusia soviética, como veremos a continuación.

\section{Los primeros balances de la experiencia con la legalización del aborto}

En julio de 1924 se publicó en alemán un artículo de Semashko titulado "Tres años de legislación soviética sobre una 'cuestión dolorosa' (El Decreto sobre el aborto)", en el cual el Comisario del Pueblo para la Salud Pública recordaba que ya habían pasado casi cuatro años desde "la así llamada 'legalización del aborto", que tanto había alborotado "a los hipócritas burgueses y a los filisteos". Según Semashko, la parte del decreto dedicada a su justificación revelaba claramente que el gobierno soviético había legalizado la interrupción voluntaria del embarazo por razones sociales (además, por supuesto, de razones médicas, las cuales no habían generado mayor debate). Caracterizaba al aborto como "un fenómeno indeseable no solo desde el punto de vista del estado como un todo, sino también desde el punto de vista de los intereses de la

\footnotetext{
17 A. Rivkin (1922). Современный взгляд на аборт-выкидыи, Орша, citado en: Waters, 1985, pp. 263-264.
} 
mujer que aborta. Esta operación es una intervención muy seria para las mujeres". El aborto podía, en ciertas circunstancias, provocar un desenlace fatal, "e incluso la más feliz de dichas operaciones, practicada de acuerdo con todas las reglas de la medicina, aun en una mujer perfectamente sana y en las condiciones más favorables" podía “acarrear consecuencias no solo en la esfera física, sino también quizás en la esfera psíquica del organismo femenino". Por lo tanto, era necesario combatir el aborto, y solo condicionalmente podía hablarse de una "legalización del aborto". Era más correcto preguntarse: “¿qué medidas deberían adoptarse para combatir este fenómeno indeseable?".

La legislación burguesa de todos los países y de todos los tiempos había luchado y luchaba contra los abortos "con las medidas punitivas más severas contra la mujer que recurre al aborto. El clero de todas las denominaciones (papas, sacerdotes católicos, pastores, rabinos, mulás) todavía practica la incitación contra la mujer que decidió abortar como una 'asesina de un alma angélica' en un feto de tres meses. No hay escorpiones que los filisteos eviten cuando se trata de lidiar con una mujer que ha recurrido al aborto". ${ }^{18}$ ¿Y cuáles eran los resultados de estas medidas punitivas "que en la mayoría de los casos no representan sino una burla cruel de la situación desesperada en la que se encuentran las mujeres en cuestión"? Semashko suministró estadísticas que mostraban un aumento imparable del aborto en todo el mundo. ¿Por qué, a pesar de toda su severidad, las medidas punitivas no solo no habían acabado con los abortos, sino que habían demostrado ser incapaces de detener su crecimiento? Porque las estadísticas mostraban que la abrumadora mayoría de las mujeres que recurrían al aborto eran desposeídas, "es decir, en la gran mayoría de los casos es la angustia, la desesperación ante su situación la que obliga a la mujer a practicarse esta operación".

Según estadísticas registradas en Ekaterimburgo, la gran mayoría de las mujeres que abortaban (el $81 \%$ ) ya habían estado embarazadas antes, y solo el 19\% decidía abortar el primer embarazo; según las mismas estadísticas, las mujeres en promedio realizaban un aborto después de un promedio de 4,5 nacimientos. "En otras palabras", concluía Semashko, "la mujer no decide practicarse esta operación porque 'no quiere tener hijos', sino porque no puede tener más hijos". Las medidas punitivas solo conseguían hacer que los abortos se practicaran clandestinamente "y dejan a las mujeres sin recursos completamente en manos de abortistas codiciosos, charlatanes y parteras ignorantes". Las "tristes estadísticas de los hospitales" ofrecían una imagen impactante de las consecuencias de este juego cruel practicado con la salud de las mujeres que se veían obligadas a recurrir a abortos clandestinos: "agujas de tejer, clavos oxidados, estacas de madera, tales son los 'instrumentos quirúrgicos' que han llevado a miles de mujeres a la

${ }^{18}$ Una referencia bíblica: "Por cuanto mi padre os cargó con un pesado yugo, yo añadiré a vuestro yugo; mi padre os castigó con látigos, pero yo os castigaré con escorpiones" (1 Reyes 12:11). 
tumba". En tales circunstancias, la tarea del poder soviético estaba claramente trazada: "sacar al aborto de la esfera de lo prohibido y de lo secreto, abolir todas las medidas punitivas contra las mujeres que optan por el aborto por razones de necesidad, y darles la oportunidad, al contrario, de practicarse esta operación en las condiciones más higiénicas posibles". El régimen soviético solo aplicaba medidas punitivas contra aquellos que buscaban capitalizar la desgracia de la mujer y que, por motivos egoístas, dañaban su salud.

Semashko pensaba que "la tarea principal" que el decreto se había fijado, "es decir, sacar a la mujer a la que la necesidad fuerza a practicarse un aborto de la esfera de la clandestinidad y arrancarla de las garras de los especuladores", se había "cumplido en gran medida". Su artículo suministraba estadísticas que mostraban que una cantidad cada vez menor de mujeres recurrían a los hospitales soviéticos debido a complicaciones surgidas de abortos practicados fuera de los mismos, a pesar de que el aborto no era punible y por ende ya no debían temer consecuencias legales. Las estadísticas también revelaban que el porcentaje de enfermedades debidas a complicaciones surgidas de abortos clandestinos mal practicados habían disminuido desde 1915. Por lo tanto, concluía Semashko, "las dos tareas principales que se impuso la ley -luchar contra el aborto clandestino y proteger la salud de las mujeres sin recursos- han sido fundamentalmente cumplidas".

Pero según Semashko, aunque el gobierno soviético había "tomado el camino correcto", todavía seguían practicándose muchos abortos clandestinos. El principal motivo residía "en el hecho de que nuestras instituciones no pueden satisfacer la necesidad en su totalidad. Muchas, demasiadas mujeres, no pueden ser aceptadas por falta de espacio". En consecuencia, el gobierno soviético había habilitado a partir de 1924 clínicas privadas para practicar el aborto a cambio de una tarifa, bajo supervisión estatal, para aquellas mujeres que pudieran costeárselo. Pero la práctica misma del aborto no era prohibida en ningún caso.

Semashko cerraba su artículo repitiendo que la legalización del aborto por parte del gobierno soviético no significaba que el mismo promoviera dicha práctica. Por el contrario, afirmaba, "la mejora en las condiciones materiales de vida durante los últimos años, el cese de la guerra y las mejoras en nuestra legislación sobre el matrimonio (la obligación de ambos padres de proveer una cuota alimentaria a sus hijos) han hecho posible circunscribir un poco más los 'aspectos sociales' relacionados con la práctica del aborto". Ahora, antes de aprobar el aborto, las mujeres eran derivadas a menudo a "los departamentos de protección de la salud de las Comisiones de Mujeres (compuestos por representantes de las secciones de mujeres). Aquí, en una conversación íntima y de camaradería, se pueden aclarar las causas que dan lugar a tal operación, considerar la posibilidad de formas alternativas de enfrentar la situación, y, si hay razones realmente apremiantes, concederle a la solicitante el permiso para practicarse la operación". Así, 
concluía Semashko, "por un lado, hemos sacado a los abortos de la esfera del secreto y de la clandestinidad, y, por otro lado, buscamos dirigirlos por un cauce organizado" (Semashko, 1924a).

Casi simultáneamente, Semashko publicó el mismo artículo en Die neue Generation, la revista editada por Helene Stöcker, una feminista interesada en la maternidad y en el cuidado infantil. Esta versión del artículo contenía un párrafo final en el que Semashko declaraba que el decreto de 1920 era un paliativo, necesario hasta que la mujer fuera liberada de las tres Kas -Küche, Kirche, Kinder (cocina, iglesia y niños)- (Semashko, 1924b).

Stöcker publicó ese mismo año un artículo titulado "La libertad de la maternidad en la nueva Rusia" en el que describía al decreto soviético de legalización del aborto como el resultado de "una ardua lucha librada en Europa Occidental y en América para asegurar el primer y más sagrado derecho de las personas, el derecho a sí mismas, a la autodeterminación sobre sus propios cuerpos, incluso para las mujeres". El artículo de Stöcker contenía una traducción del decreto soviético, al que describía como "la realización pacífica y objetiva de una demanda por la que los hombres y las mujeres más lúcidos de Europa han trabajado en vano hasta la fecha. Ciertamente, en Rusia la consecución de estas reformas se debió también al trabajo preparatorio de luchadoras tan extraordinarias por la protección de la madre como Alexandra Kollontai, anteriormente miembro del ejecutivo ruso y ahora embajadora en Noruega, así como de la Sra. Lebedeva, que dirige el departamento para la protección de las madres y de los niños" (Stöcker, 1924, pp. 19, 21).

Los principales voceros de la política soviética sobre la legalización del aborto, como el médico A.B. Genss, el portavoz oficial de la División para la Protección de la Maternidad y de la Infancia del Comisariado de Salud Pública, insistieron en que la legalización había reducido las amenazas para la salud de la mujer. Genss presentó estadísticas que mostraban que solo el $12 \%$ de las mujeres que solicitaban practicarse un aborto estaban embarazadas por primera vez (es decir, que el $88 \%$ ya eran madres de uno o más hijos), y en la Tercera Conferencia Panrusa para la Protección de la Maternidad y la Infancia, celebrada en 1925, acusó a los oponentes de la legalización del aborto de ser esclavos de "la moral burguesa" (Gross Solomon, 1992a, p. 80, nota 100, y p. 64).

En un folleto publicado en Viena en 1926 con el título ¿Qué enseña la despenalización del aborto en la Rusia soviética?, Genss resumió el material compilado sobre el tema del aborto por el Departamento Materno-Infantil de Moscú e intentó analizarlo estadísticamente aun en aquellos casos donde las condiciones dificultaban semejante tratamiento -es decir, particularmente, entre el campesinado sin educación-. Genss llegó a la conclusión de que el $45 \%$ de los abortos se practicaban por razones medicinales y el 
$55 \%$ por razones sociales. La influencia de la escasez de viviendas se reflejaba claramente en el hecho de que de 100 mujeres que vivían con su cónyuge en una pieza, solo 14 abortaban, mientras que de 100 mujeres que vivían en una pieza con 4 o más personas, 44 abortaban. Genss presentó de la siguiente manera los resultados de su estudio:

“El trabajo prueba que cualquier compulsión o amenaza de castigo solo arrojará a la mujer que quiere abortar en manos de la curandera y, por lo tanto, a la enfermedad y a la muerte. Como dijo un médico expresamente: 'Una mujer que ha decidido poner fin a su embarazo no retrocede ante nada en el mundo'. A diferencia de todos los otros países, todas las mujeres en el estado proletario pueden abortar si así lo desean. Si lo necesitan, pueden incluso practicarse un aborto a expensas del estado. La consecuencia es que no hay fatalidades en las interrupciones artificiales del embarazo. Dado que la mujer que se practica un aborto no debe enfrentar ningún castigo, sino que solo se castiga a los curanderos, aún en caso de un aborto mal practicado la mujer recurre con tiempo al hospital" (Genss, 1926, ver también la reseña de Levy-Lenz, 1926).

En una reunión del Consejo del Instituto Alemán de Ciencias Sexuales celebrada en Berlín el mismo año, Magnus Hirschfeld, el padre fundador del movimiento de liberación homosexual, afirmó que la Unión Soviética -que había despenalizado la homosexualidad masculina en 1922- estaba a la vanguardia de las nuevas leyes sobre la vida sexual, entre las cuales incluyó la despenalización del aborto (Hirschfeld, 1926). ${ }^{19}$

\section{Conclusión}

La Rusia soviética, a iniciativa de las mujeres trabajadoras, fue el primer país en el mundo en legalizar la interrupción voluntaria del embarazo y en permitir su práctica gratuita en hospitales públicos, aun cuando las organizaciones feministas rusas de aquel entonces no incluían dicha demanda en sus programas. El decreto soviético de legalización del aborto coronó toda una serie de medidas legislativas destinadas a instaurar la igualdad legal entre la mujer y el hombre, así como a asegurar la protección legal de las mujeres trabajadoras. En este artículo describimos el proceso que concluyó en la adopción de dicha legislación y analizamos brevemente los resultados de su aplicación en Rusia.

La legalización del aborto fue justificada por los representantes del gobierno soviético como una medida requerida por la precaria situación en la que se encontraban las mujeres trabajadoras y campesinas, si bien existió un debate en la Rusia soviética sobre los motivos y la justificación del aborto que intentamos documentar en el presente

\footnotetext{
${ }^{19}$ El decreto soviético de legalización del aborto tuvo una amplia repercusión en el exterior, en particular en Alemania, el país que tenía el Partido Comunista más numeroso después de la Unión Soviética. Un análisis de este fenómeno queda fuera del alcance del presente trabajo, pero ver: Frauensekretariats der Kommunistischen Partei Deutschlands, 1922; Gutmann, 1923; Roesle, 1925a y 1925b; Ruben-Wolf, 1929.
} 
trabajo. De la posición de los representantes del gobierno bolchevique se desprendía que la práctica del aborto debía ser gradualmente reemplazada por la planificación del embarazo y por la socialización del cuidado y de la educación de los niños, junto con el resto de las tareas domésticas que recaían sobre el trabajo impago de las mujeres. La abolición de la esclavitud doméstica, a su vez, crearía las bases materiales para la emancipación real de la mujer y para el surgimiento de una nueva forma de familia.

Los proyectos bolcheviques para la liberación de las mujeres chocaron con los límites brutales impuestos por la herencia del atraso ruso, la destrucción causada por la Primera Guerra Mundial, la guerra civil y la intervención extranjera, y el aislamiento de la revolución, por lo que debieron ser parcialmente revertidos con la adopción de la Nueva Política Económica (NEP) en marzo de 1921, para finalmente ser liquidados con el ascenso de Stalin, quien adoptó un Decreto sobre la prohibición del aborto el 27 de junio de $1936 .{ }^{20}$

20 О запрещении абортов, увеличении материальной помощи роженицам, установлении государственной помощи многосемейным, расширении сети родильных домов, детских яслей и детских садов, усилении наказания за неплатеж алиментов. ЦИК и СНК СССР 27 июня 1936 г. [Sobre la prohibición del aborto, el aumento de la asistencia material a las mujeres en el parto, el establecimiento de asistencia estatal para las familias múltiples, la expansión de la red de maternidades, guarderías y jardines de infantes, y un mayor castigo por el no pago de la pensión alimenticia. El Comité Ejecutivo Central y el Consejo de Comisarios del Pueblo de la URSS el 27 de junio de 1936.]. URL: http://istmat.info/node/24072. 


\section{Apéndice I: Resolución de los Comisariados del Pueblo de Salud y de Justicia: "Sobre la protección de la salud de las mujeres" (18 de noviembre de 1920) ${ }^{21}$}

Durante las últimas décadas, el número de mujeres que recurren a la interrupción artificial del embarazo ha crecido tanto en Occidente como en este país. La legislación de todos los países combate este mal mediante el castigo de la mujer que decide practicarse un aborto y del médico que lo practica. Sin arrojar resultados favorables, este método de lucha contra el aborto ha impulsado la práctica de abortos clandestinos y ha hecho de las mujeres víctimas de charlatanes mercenarios y a menudo ignorantes, que hacen una profesión de las operaciones secretas. Como resultado, hasta el 50 por ciento de estas mujeres desarrollan infecciones en el transcurso de la operación, y hasta el 4 por ciento de ellas mueren.

El Gobierno obrero y campesino es consciente de este grave mal a la comunidad. Combate este mal por la propaganda contra los abortos entre las mujeres trabajadoras. Al trabajar por el socialismo y la introducción de la protección de la maternidad y de la infancia en gran escala, se siente seguro de lograr la desaparición gradual de este mal. Pero en la medida en que las supervivencias morales del pasado y las difíciles condiciones económicas del presente todavía obligan a muchas mujeres a recurrir a esta operación, los Comisariados del Pueblo de Salud y de Justicia, deseosos de proteger la salud de las mujeres, y teniendo en cuenta que el método de la represión en este campo ha fracasado por completo en lograr este objetivo, han decidido:

(1) Permitir que este tipo de operaciones se practique libremente y sin cargo alguno en los hospitales soviéticos, donde las condiciones necesarias para minimizar el daño de la operación estén aseguradas.

(2) Prohibir absolutamente a cualquiera que no sea un médico llevar a cabo esta operación.

(3) Cualquier enfermera o partera que sea encontrada culpable de realizar una operación de este tipo será privada del derecho a la práctica y juzgada por un tribunal popular.

21 Постановление Народных Комиссариатов Здравоохранения и Юстиции. Об охране здоровья женщин. 1920.11.18. Распубликовано в № 259 Известий Всероссийского Центрального Исполнительного Комитета Советов от 18 ноября 1920 года. Источник: Собрание узаконений и распоряжений правительства за 1920 2. Управление делами Совнаркома СССР. М. 1943, стр. 681. [Resolución de los Comisariados del Pueblo de Salud y de Justicia, "Sobre la protección de la salud de las mujeres". 18 de noviembre de 1920. Publicado en el n 259 de las Noticias del Comité Ejecutivo Central de los Soviets del 18 de noviembre de 1920. Fuente: Colección de legislación y órdenes del gobierno para 1920. Gestión de los asuntos del Consejo de Comisarios del Pueblo de la URSS, Moscú, 1943, p. 681.]. URL: http://istmat.info/node/42778 
(4) Un doctor que lleve a cabo un aborto en su práctica privada con fines mercenarios será llamado a rendir cuentas ante un tribunal popular.

Comisario del Pueblo de Salud

N. Semashko

Comisario del Pueblo de Justicia

Kurskii

(Publicado en el n. ${ }^{\circ} 259$ del Izvestia del Comité Ejecutivo Central de los Soviets del 18 de noviembre de 1920).

Apéndice II: La protección de la madre y el niño. La posición de la Rusia soviética sobre el tema de la protección maternal e infantil y del aborto. Tesis del camarada Semashko, Comisario del Pueblo de Salud (3 de julio de 1920)22

(1) La salud de la madre y de las adolescentes es un requisito previo necesario de una población capaz de trabajar. En un momento en que la organización del trabajo ha adquirido una importancia tan trascendental, el poder soviético y toda la población trabajadora deben prestar especial atención a este hecho.

(2) Todos los órganos del gobierno soviético deben participar de alguna forma en la creación, ampliación y diseño de las instituciones que sirvan a la protección maternal e infantil, tales como residencias para madres e hijos, hogares de maternidad, guarderías, jardines de infantes, centros de asesoramiento para mujeres embarazadas, madres y niños, etc. Deben garantizar la difusión de los conocimientos de higiene necesarios para la protección de la madre y del niño, el cuidado del bebé, etc.

(3) Por razones obvias, la cuestión de la protección maternal e infantil debe ser objeto de especial atención por parte de las mujeres trabajadoras (secciones de mujeres del

${ }^{22}$ Semashko (1920, pp. 34-36). El título en español: “La protección de la madre y el niño. La posición de la Rusia soviética sobre el tema de la protección maternal e infantil y del aborto. Tesis del camarada Semashko, Comisario del Pueblo de Salud." La Internacional de Mujeres Comunistas. Revista Mensual. Editada en nombre del Ejecutivo de la Internacional de Mujeres y del Secretariado Internacional de Mujeres Comunistas en Moscú por Clara Zetkin. Volumen 1, Número 1, abril de 1921, pp. 34-36. Una versión alemana del decreto soviético de legalización del aborto aparece inmediatamente después de las tesis de Semashko ante el Zhenotdel: Verordnung des Volkskommissariat für Gesundheitswesen und soziale Fürsorge und des Volkskommissariat der Rechtspflege in Sowjet-Rußland. Die Kommunistische Fraueninternationale. Monatschrift. Herausgegeben im Auftrag der Exekutive der Fraueninternationale und dem internationalen kommunistischen Frauensekretariat in Moskau von Clara Zetkin, 1 (1), April 1921, p. 36 . El título en español: "Decreto del Comisariado del Pueblo para la Atención de la Salud y el Bienestar Social y del Comisariado del Pueblo de Justicia en la Rusia soviética." La Internacional de Mujeres Comunistas. Revista Mensual. Editada en nombre del Ejecutivo de la Internacional de Mujeres y del Secretariado Internacional de Mujeres Comunistas en Moscú por Clara Zetkin, 1 (1), abril de 1921, p. 36]. 
Partido). Todo el trabajo en este campo tiene que hacerse con la participación más entusiasta de las organizaciones de mujeres.

(4) Se debe librar una lucha decidida contra todo aquello que perjudique, de una manera u otra, la salud de la madre y amenace el crecimiento normal de la población de la república obrera. En particular, es necesario luchar contra la interrupción artificial del embarazo (aborto), que daña la salud de las mujeres y pone en peligro el crecimiento de la población, si este fenómeno se transforma en un fenómeno de masas.

(5) La cuestión del aborto no puede ser contemplado desde el punto de vista liberalanarquista del "derecho de la mujer individual", sino pura y exclusivamente desde el punto de vista de los intereses de la sociedad (del colectivo), a la cual los abortos causan un daño indudable.

(6) En la sociedad capitalista, los abortos son el resultado de la difícil situación económica de las mujeres de las clases trabajadoras, del embrutecimiento moral de las mujeres de las clases privilegiadas, así como de la esclavitud legal de las mujeres (el matrimonio por conveniencia o por necesidad, la madre soltera, etc.)

(7) La realización del socialismo elimina todas estas causas de la interrupción artificial del embarazo. Con la plena realización del socialismo desaparecen todos los motivos para el aborto.

(8) Las medidas represivas para combatir el aborto producen el efecto contrario: el aborto se convierte en un acto ilegal y es practicado en secreto. Realizado por parteras ignorantes, el aborto perjudica gravemente la salud de las mujeres, pero también los médicos con examen estatal y doctorado que realizan abortos en sus prácticas privadas viven a expensas de la miseria de las mujeres embarazadas.

(9) El aborto ya no debe practicarse en lugares secretos; esto es, en casos inevitables, debe llevarse a cabo en forma gratuita y sin cargo en las clínicas estatales, donde a la mujer embarazada se le garantice la máxima seguridad en esta operación. Está estrictamente prohibido practicar un aborto fuera de las clínicas estatales. Los médicos que realicen esta operación en su práctica privada deberán comparecer ante un Tribunal Popular.

(10) La única medida racional para combatir el aborto es el aumento de la actividad en el campo de la protección maternal e infantil. Al mismo tiempo, la población debe ser informada adecuadamente sobre las medidas adoptadas por el Estado.

(11) Las mujeres organizadas y sus órganos de trabajo deben incluir este tema en su orden del día. Toda mujer consciente debe saber exactamente qué le ofrece el Estado a ella como madre y a sus hijos en términos de protección, así como dónde están ubicadas las instituciones relevantes en su distrito. El trabajo de toda comunista es agitar en cualquier caso entre las mujeres para el cuidado de la maternidad y contra el aborto, instruir a las errantes, apoyar a las vacilantes, y arrancar a aquellas mujeres que han decidido realizar la operación seria del aborto de las garras de los especuladores y de los 
que practican el aborto por motivos mercenarios, y derivarlas a las instituciones soviéticas pertinentes.

(12) Se debe prestar especial atención a las fábricas y a las empresas, donde el mal [Uebel] del aborto últimamente se ha vuelto muy popular. Es tarea de los departamentos relevantes de los Comisariados del Pueblo de Salud y de Bienestar Social, junto con los órganos de las mujeres, trabajar conjuntamente para extender la protección maternal e infantil entre las masas trabajadoras y hacer que alcance una extensión sin precedentes.

(13) El poder soviético ha hecho mucho en el campo de la protección materno-infantil y de la asistencia social para la madre y el niño. La tarea de los grupos de mujeres es garantizar que todas las órdenes, decretos y decisiones adoptados hasta ahora por el Comisariado del Pueblo sean conocidos y ejecutados. No importa cuán difíciles sean las condiciones en las que vivimos, la salud de la madre y del niño no debe sufrir, porque el futuro de toda nuestra población de clase trabajadora depende del bienestar de la madre y del normal desarrollo del niño.

(14) El poder soviético ha hecho más en el curso de los tres años de su existencia en el área de la protección maternal e infantil de lo que ha hecho la burguesía durante siglos. El fin de la guerra civil y la superación de la decadencia económica y del caos nos permiten realizar plenamente nuestro programa en esta área también. Pero con ello desaparecerán todos los vestigios del antiguo orden, incluidos los abortos, que dañan la salud de la madre y del niño y, por lo tanto, los intereses de la nación, e inhiben su desarrollo físico.

\section{Referencias bibliográficas}

Conius, E. (1933). Protection of Motherhood and Childhood in the Soviet Union, MoscowLeningrad: State Medical Editorship.

Engelstein, L. (1991). Abortion and the Civic Order: The Legal and Medical Debates. En B. Evans Clements et al. (Eds.). Russia's Women (pp. 185-207), Berkeley, CA: University of California Press.

Frauensekretariats der Kommunistischen Partei Deutschlands (1922). Mutter- und Kinderschutz. Denkschrift des Frauensekretariats der Kommunistischen Partei Deutschlands an die Zentrale der Partei, betreffend die $\S \S 218$ und 219 des Strafgesetzbuches für das deutsche Reich. Die Kommunistische Fraueninternationale. Monatschrift. Herausgegeben im Auftrag der Exekutive der Fraueninternationale

und dem internationalen kommunistischen Frauensekretariat in Moskau von Clara Zetkin. 2 (3/4), marzo/abril, 500-505. 
Frencia, C. y Gaido, D. (2016). El marxismo y la liberación de las mujeres trabajadoras: De la Internacional de Mujeres Socialistas a la Revolución Rusa. Santiago de Chile: Ariadna Ediciones. URL: http://www.oapen.org/search?identifier=619630

Frencia, C. y Gaido, D. (2018). El feminismo y el movimiento de mujeres socialistas en la Revolución Rusa. Santiago de Chile: Ariadna Ediciones.

URL: www.oapen.org/record/1000434

Genss, A.B. (1926). Was lehrt die Freigabe der Abtreibung in Sowjet-Russland?, Heft I: Der Abort auf der Lande, vol. 1. Wien: Agis Verlag.

Genss, A. B. (1926). Der Abort in der Russischen Sozialistischen Föderativen Sowjet-Republik, vol. 2. Wien: Agis Verlag.

Goldman, W. Z. (2011). La mujer, el estado y la revolución: Política familiar y vida social soviéticas, 1917-1936. Buenos Aires: Instituto del Pensamiento Socialista.

Gross Solomon, S. (1992a). The Demographic Argument in Soviet Debates over the Legalization of Abortion in the 1920's. Cahiers du monde russe et soviétique, 33 (1), 5981.

Gross Solomon, S. (1992b). The Soviet Legalization of Abortion in German Medical Discourse: A Study of the Use of Selective Perceptions in Cross-Cultural Scientific Relations. Social Studies of Science, 22 (3), 455-485.

Gutmann, K. (1923). Zum internationalen Kampf gegen die Bestrafung der Abtreibung. En Die Kommunistische Fraueninternationale. Monatschrift. Herausgegeben im Auftrag der Exekutive der Fraueninternationale und dem internationalen kommunistischen Frauensekretariat in Moskau von Clara Zetkin, 3 (5), mayo, 15-24.

Healey, D. (2018). Homosexualidad y Revolución. Buenos Aires: Final Abierto.

Hirschfeld, M. (1926). Sexualreform im neuen Russland, Das Neue Russland: Monatsschrift für Kultur- und Wirtfschaftsfragen, 3 (11/12), 39-40.

Kollontai, A. (1921). L'ouvrière et la paysanne dans la République soviétique. Paris: Librairie de L'Humanité.

Kollontai, A. (1922). Положение женщиины в эволюици хозяйства: лекции читанные в Университете имени Я.М. Свердлова. Moscú: Gos. Editorial.

Kollontai, A. (1978). Selected Writings, Translated with an introduction and commentaries by Alix Holt. Westport, Conn.: Lawrence Hill Co., Publishers, Inc.

Krupskaya, N. (1920). Война и деторождение. Коммунистка, 1-2. Reproducido en Педагогические сочинения, tomo 6 (pp. 7-12). Moscú: Editorial de la Academia de Ciencias Pedagógicas, 1959.

Lenin, V. (1913). La clase obrera y el neomalthusianismo, Pravda, 102, 5 de mayo de 1913, en V. Lenin, Obras completas (pp. 478-480), tomo 19. Madrid: Akal. (ed. 1971).

Levy-Lenz, L. (1926). Der Abort in Sowjet-Russland, Das Neue Russland: Monatsschrift für Kultur- und Wirtfschaftsfragen, 3 (7/8), 36.

Lewin, M. (2005). The Soviet Century. London: Verso. 
Nakachi, M. (2016). Liberation without Contraception? The Rise of the Abortion Empire and Pronatalism in Socialist and Postsocialist Russia. En R. Solinger y M. Nakachi (Eds.), Reproductive States: Global Perspectives on the Invention and Implementation of Population Policy (pp. 290-328). Oxford: Oxford University Press.

Roesle, E. (1925a). Die Statistik des legalisierten Abortus, Zeitschrift für Schulgesundheitspfiege und soziale Hygiene, 38 (10), 445-455.

Roesle, E. (1925b). Zur Statistik des legalisierten Abortus. Das Neue Russland: Monatsschrift für Kultur- und Wirtfschaftsfragen, 2 (9/10), 38-39.

Ruben-Wolf, M. (1929). Abtreibung oder Verhütung?. Berlin: Internationaler Arbeiter Verlag.

Semashko, N. (1920). Mutter- und Kinderschutz. Sowjet-Rußlands Stellung zur Frage des Mutter- und Kinderschutzes und der Abtreibung. Thesen des Genossen Semaschko, Volkskommissar für das Gesundheitswesen. Die Kommunistische Fraueninternationale. Monatschrift. Herausgegeben im Auftrag der Exekutive der Fraueninternationale und dem internationalen kommunistischen Frauensekretariat in Moskau von Clara Zetkin. 1 (1), April 1921, 34-36.

Semashko, N. (1924a). Drei Jahre Sowjetgesetzgebung in einer 'wunden Frage' (Das Dekret über die Aborte). Das Neue Russland: Monatsschrift für Kultur- und Wirtfschaftsfragen, 1 (3-4), 27-29.

Semashko, N. (1924b). Drei Jahre Sowjetgesetzgebung in der 'Abtreibungsfrage'. Die neue Generation, 20 (7/8), 172-178.

Stöcker, H. (1924). Freiheit der Mutterschaft im neuen Russland. Das Neue Russland: Monatsschrift für Kultur- und Wirtfschaftsfragen, 1 (1), 19-21.

Waters, E. (1985). From the Old Family to the New. Work, Marriage and Motherhood in Urban Soviet Russia, 1917-1931, Ph.D. thesis, University of Birmingham, mimeo.

Wood, E. A. (1997). The Baba and the Comrade: Gender and Politics in Revolutionary Russia. Bloomington: Indiana University Press.

Zetkin, C. (1907). Zur Frage des Frauenwahlrechts, bearbeitet nach dem Referat auf der Konferenz sozialistischer Frauen zu Mannheim, Dazu drei Anhänge: I. Resolution der Konferenz sozialistischer Frauen zu Mannheim, das Frauenwahlrecht betreffend; II. Entwicklung des Frauenwahlrechts; III. Eine sozialistische Enquete über die sofortige Einführung des Frauenwahlrechts. Berlin: Buchhandlung Vorwärts.

URL: http://www.deutschestextarchiv.de/book/show/zetkin_frauenwahlrecht2_1907. (consultado 10/10/2017).

Zetkin, C. (1921). Die beiden Novemberrevolutionen und die Frauen. Die Kommunistische Fraueninternationale. Monatschrift. Herausgegeben im Auftrag der Exekutive der Fraueninternationale und dem internationalen kommunistischen Frauensekretariat in Moskau von Clara Zetkin. 1 (8/9), November, 1-13. 
52 | Los orígenes del decreto soviético de legalización del aborto (1920)

Para citar este artículo:

Frencia, Cintia y Gaido, Daniel (2018). Los orígenes del decreto soviético de legalización del aborto (1920). Anuario de la Escuela de Historia Virtual, 14, 2652. 